
\title{
CIÊNCIANATURA
}

\section{Qualidade ambiental da área urbana de Salto do Jacuí/RS}

Environmental quality of the urban area of Salto do Jacuí / RS

\author{
Ismael Luiz Hoppe ${ }^{1}$, Cássio Arthur Wollmann ${ }^{2}$ e Aline Nunes da Silva ${ }^{3}$ \\ ${ }^{1}$ Licenciado em Geografia, aluno de Mestrado PPGGEO, Universidade Federal de Santa Maria, Santa Maria, Brasil \\ ismael.hoppe@hotmail.com \\ ${ }^{2}$ Professor Orientador da Universidade Federal de Santa Maria, Santa Maria, Brasil \\ cassio_geo@yahoo.com.br \\ ${ }^{3}$ Aluna de Graduação em Geografia Bacharelado da Universidade Federal de Santa Maria, Santa Maria, Brasil \\ alinendeca@hotmail.com
}

\section{Resumo}

Este trabalho tem como objetivo analisar a qualidade ambiental da área urbana de Salto do Jacuí-Rio Grande do Sul, que está localizada no noroeste do estado na bacia hidrográfica do Alto Jacuí. A análise foi realizada por meio de mapeamento de caracteristicas negativas que venham a comprometer a qualidade do ambiente urbano: uso do solo, poluição, espaços livres, verticalidade das edificações, pontos de enchentes, densidade populacional e cobertura vegetal. O mapeamento dos atributos negativos e o posterior cruzamento de mapas determinou a qualidade ambiental urbana. Foram realizados no software de geoprocessamento ArcGis10. Para fazer as cartas foi utilizada como base a imagem de satélite do Software Google Earth, após ter sido georreferenciada, foram identificados, mapeados e quantificados os espaços livres, uso do solo e a cobertura vegetal (desertos florísticos). Para as demais cartas foram realizados trabalho de campo e observações. Com esta análise foi possivel observar que a área urbana do Salto do Jacui não apresenta uma baixa qualidade ambiental, e sim apresenta uma média e alta qualidade ambiental.

Palavras-chave: Urbano. Qualidade ambiental. Salto do Jacuí.

\section{Abstract}

This work aims to analyze the environmental quality of the urban area of Salto do Jacui - Rio Grande do Sul, which is located in the northwest of the state in the catchment area of. The analysis was carried out by mapping negative characteristics that would compromise the quality of the urban environment: land use, pollution, free spaces, buildings verticality, flood points, population density and vegetation cover. The mapping of the negative attributes and the subsequent crossing of maps determined the urban environmental quality. They were performed in the ArcGIS10 geoprocessing software. In order to make the charts, the satellite image of the Google Earth Software was used as base, after being georeferenced, free spaces, land use and vegetation cover were identified, mapped and quantified. For the other letters, fieldwork and observations were made. With this analysis it was possible to observe that the urban area of Salto do Jacui does not present a low environmental quality, but rather presents a medium and high environmental quality.

Keywords: Urban. Environmental Quality. Salto do Jacui.. 


\section{Introdução}

Após a década de 1950, a urbanização teve um crescimento acelerado no Brasil, contribuindo significativamente para a redução da qualidade ambiental das cidades brasileiras de grande e médio porte. Nestas cidades o crescimento urbano aconteceu em virtude da degradação do meio natural com danos à saúde e a qualidade de vidas dos seus habitantes. A extinção da vegetação, com a intensa pavimentação e com as atividades humanas que expandem no espaço urbano, as quais contribuem para a produção de problemas ambientais que são prejudiciais à saúde das cidades como a poluição do ar. Ilhas de calor, deslizamentos de encostas, inundações, e contaminação dos recursos hídricos pelas indústrias e resíduos domésticos. Lombardo (1985) salienta que a urbanização desfreada, sem controle causa problemas ecológicos como o desequilíbrio crescente da população e dos meios materiais, e com isso ocorre a contaminação em todas as suas manifestações.

As cidades são caracterizadas como uma contínua, cumulativa e acentuada 'derivação antrópica' do ambiente, suficiente para provocar uma série de mudanças na atmosfera, até mesmo em sua própria composição química, tanto sobre a área urbana e até mesmo transpor para ambientes vizinhos (MONTEIRO, 1990a). Os ambientes urbanos salientam-se pela intensidade com que tais impactos correm especialmente no perímetro da faixa de cobertura urbana, na qual as suas características climáticas acentuadamente alteradas quanto aos aspectos da composição do ar, temperatura, radiação, umidade relativa e velocidades dos ventos (LANDSBERG, 1970). Além dos mais variados problemas socioambientais pertinentes na cidade da urbanização produz alterações no clima local causando o clima urbano que Monteiro (1976) define como um sistema que abrange o clima de um determinado espaço terrestre e a sua urbanização.

Com isso, o presente artigo teve como objetivo geral analisar a qualidade urbana do município de Salto do Jacuí com base na metodologia desenvolvida por NUCCI (2008). A qual é realizada por meio de mapeamento de características negativas que venham a comprometer a qualidade do ambiente urbano sendo eles o uso do solo, poluição, espaços livres, verticalidade das edificações, pontos de enchentes, densidade populacional e cobertura vegetal.

\subsection{Caracterização da área}

A área de estudo é a cidade do Salto do Jacuí pertencente ao estado do Rio Grande do Sul, a zona urbana localiza-se a uma latitude $29^{\circ} 05^{\prime} 18^{\prime \prime}$ sul e a uma longitude $53^{\circ} 12^{\prime} 45^{\prime \prime}$ oeste, está localizado na bacia hidrográfica do Alto, a qual oficialmente pertence a Mesorregião do Noroeste Rio-grandense e à Microrregião Geográfica de Cruz Alta, Salto do Jacuí faz divisa com cinco municípios sendo eles: Estrela Velha e Júlio de Castilho ao sul, Arroio do Tigre ao sudeste, Jacuizinho de nordeste ao leste e Fortaleza dos Valos de Oeste ao Norte. E seu principal acesso dá-se pela BR 481 (FEE, 2017), (figura 1).

A população total segundo IBGE é de 12.460 habitantes, sendo 10.208 na área urbana e 1.672 na área rural e densidade demográfica é de 23,4 habitantes $/ \mathrm{km}^{2}$, e o Índice de Desenvolvimento Humano (IDH) é de 0,749 (IBGE, 2017). A origem do nome do município é indígena "Jacuí" que significa Rio dos Jacús e Rio das Canoas, e também por haver um grande "Salto" (queda d'água). A cidade de Salto do Jacuí está a uma altitude média de 320 metros acima do nível do mar. Salto do Jacuí encontra-se a uma distância de $220 \mathrm{~km}$ de Porto Alegre, capital do Estado do Rio Grande do Sul (em linha reta), e sua área total é de 507,384 km² (IBGE, 2017).

Saldo do Jacuí é conhecida como a Capital Gaúcha da Energia Elétrica, tem uma relação especial com as águas, pois 


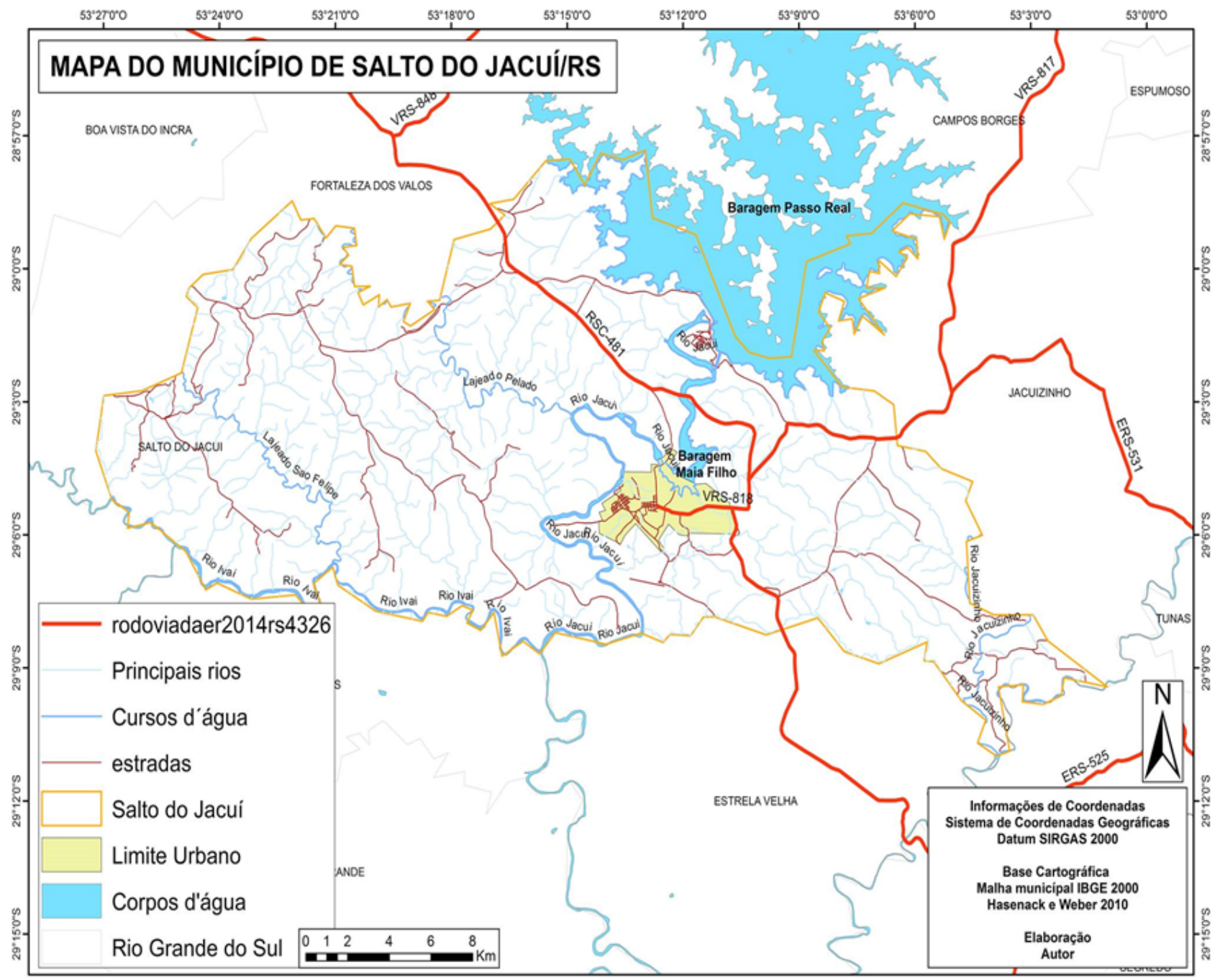

Figura 1 - Município do Salto do Jacuí

possui o maior lago artificial do Rio Grande do Sul - Bacia do Passo Real e a Represa Engenheiro Maia Filho. O complexo hidrelétrico do sistema Jacuí é responsável por $65 \%$ da energia gerada pela CEEE no Estado e $35 \%$ da carga consumida pelos gaúchos (REDE CIDADES, 2017).

\section{Fundamentação Teórica}

Executar um trabalho de espacialização da qualidade ambiental é um grande desafio, pois não existe uma receita técnica e nem um ponto de vista teórico-metodológico pronto Monteiro (1987). Conforme Sukopp e Werner (1991 apud NUCCI, 2008) a urbanização interfere diretamente na qualidade ambiental, devido às alterações que provoca no ar, solo, água e nos organismos.

Entre as principais características que os autores citam sobre a ecologia das cidade sendo elas, a produção e o consumo de energia secundária são altos; grande importação e exportação de materiais, enorme quantidade de dejetos; elevação em vários metros da superfície do solo (verticalização); forte contaminação do ar, do solo e da água; diminuição das águas subterrâneas; destruição do solo; desenvolvimento de um clima tipicamente urbano, com maiores temperaturas e baixa umidade relativa (ilha de calor); espaço heterogêneo e em mosaico; desequilíbrio em 
favor dos organismos consumidores, baixa produtividade primária e débil atividade dos organismos detritívoros; mudanças fundamentais nas populações vegetais e animais.

Segundo Monteiro (1987), o aumento exercido pela concentração da população e das atividades produzidas pela urbanização e industrialização, concorrem para intensificar as modificações do meio ambiente, com o comprometimento da qualidade de vida. De acordo com Nucci (1999), com a urbanização ocorre um crescimento da impermeabilização ocasionada pela ocupação do solo por concreto. Os espaços livres de vegetação e os corpos d'água não encontram lugar pela conquista do espaço ocasionada pela urbanização. A verticalização faz com que a superfície de concreto, tenha uma alta capacidade térmica. Este processo leva a uma diminuição da evaporação, a um aumento da rugosidade e da capacidade térmica da área.

As características já citadas atuam de forma direta para a redução da qualidade ambiental, que poderá ser maior ou menor em função do tamanho, tipologia e funcionalidade da malha urbano. Verifica-se que o atual modelo urbano se encontra insustentável do ponto de vista dos recursos energéticos e ambientais. Por esse ângulo Assis (2010) destaca que os padrões das cidades formadas pelo Movimento Moderno não apresentam ser mais sustentável. De fato, a cidade moderna, em consequência de seu modo de organização e acumulo de atividades, acarretam diversas mudanças significativas sobre suas esferas de suporte naturais, tais como o subsolo, solo e atmosfera.

A verticalização aumenta a superfície de absorção de calor, e a superfície impermeabilizada faz com que as águas escoem mais rapidamente diminuindo a umidade do ar, evaporação, transpiração o que ocasiona o aumento do aquecimento, gerando problemas relacionados com a qualidade ambiental. Com a verticalização acarreta o surgimento do sombreamento, causando contrastes térmicos entre a parte sombreada e a ensolarada. A ocupação do espaço aéreo, e o aumento do trafego ocasionam um aumento de gases e poeiras na atmosfera, possibilitando um aumento da poluição.

Com a verticalização, sucede um aumento da densidade populacional que leva a uma queda da qualidade ambiental. A aglomeração de pessoas confinadas em pequenos espaços faz com que passam por desconforto, riscos de doenças, problemas de alimentação, suprimento de água e dificuldade para arrumar espaço para depósito de seus resíduos. (DOUGLAS, 1983).

Para Nucci (1999) os níveis de qualidade ambiental e adensamento populacional são inversamente proporcionais, ou seja, quanto mais se verticaliza, mais a qualidade do ambiente diminui. Assim no planejamento ambiental deve preocupar-se com a diminuição do adensamento urbano (verticalização), evitando a ocupação de fundo de vales, e criar um programa de arborização, controlando a disposição de resíduos sólidos, para melhoria da qualidade ambiental.

Lima (2013) salienta que, em relação à parte conceitual da qualidade ambiental, se refere ao padrão a ser estabelecido e/ou alcançado de satisfação ambiental. Considerada então, como um coeficiente que pode indicar o grau do comprometimento ambiental, referindo-se à associação dos fatores ecológicos e socioeconômicos, assim essa "aualidade" significa "nronriedade. ou condicão das coisas ou das nessoas"

Já para Perloff (1973), compreender o conceito de qualidade ambiental urbana é entender o meio ambiente urbano enquanto sistema aberto. Neste sentido a cidade é um sistema único, complexo e interativo, onde a sociedade e a natureza interagem na formação de derivações ambientais, que podem acarretar em uma melhora ou piora da qualidade do ambiente. Diante das alterações ambientais promovidas pela urbanização, mostra-se a necessidade de aderir a políticas públicas de planejamento ambiental que garantam a sustentabilidade e diminuem os impactos contrários do mau uso do solo urbano. 
De acordo com Lima (op. cit.) a observação da qualidade ambiental manifesta da necessidade de aprimorar as condições ambientais e de vida nos centros urbanos que, em muitas ocasiões, tem uma relação direta com um adequado planejamento e, indiretamente, com questões sociais, econômicas e culturais.

Lima; Amorim (2006) observam com mais enfoque os problemas relacionados ao meio ambiente nas cidades, consequentemente, os estudos associados com a qualidade do ambiente urbano são capazes de contribuir para aperfeiçoar o planejamento a partir da geração de políticas eficazes para tornar o uso e a ocupação do solo dos centros urbanos menos impactantes ao meio ambiente, e melhorar a qualidade de vida da população, que depende de um ambiente ecologicamente equilibrado.

Para Morato (2008), a qualidade do ambiente urbano vem se transformando em um dos aspectos mais significativos para a definição da qualidade de vida da população. No aspecto social, o acréscimo da conscientização de que problemas ambientais podem afetar a saúde da população, associado ao crescimento da urbanização, cria a necessidade de uma nova avaliação da qualidade ambiental das áreas urbanas.

O cuidado, portanto, é agrupar o maior número de dados cartografáveis da zona de estudo para depois fazer o cruzamento e criação de um diagnóstico ambiental especializado. De um modo geral, os fatores ambientais são parâmetros que podem ter a capacidade de relatar um estado ou situação dos fenômenos que ocorrem no ambiente (LIMA, 2013). Em relação a proposta de Nucci (1996) o mapeamento dos atributos negativos que vem atrapalhar a qualidade do ambiente urbano, são: uso do solo, poluição, espaços livres, verticalidade das edificações, pontos de enchentes, densidade populacional e cobertura vegetal.

Lima (2012) ressalta que a metodologia de Nucci possui como principal atribuição a representação de atributos ambientais negativos para sua subsequente analise integrada, com base no cruzamento destes para chegar a um resumo, ou seja, a carta de qualidade ambiental, por meio de álgebra de mapas. Estas cartas, quando sobrepostas, concedem à geração de mapas sínteses com as informações espacializadas da qualidade ambiental da área estudada. A sobreposição é realizada através de software de geoprocessamento tais como ArcGis, entre outros.

Nucci (1998) enfoca que o levantamento de como a cidade utiliza seu solo é de importante grandeza, pois está diretamente relacionado com as características físicas que a cidade possui. Sendo assim, uma carta de uso do solo torna-se um importante instrumento para se fazerem deduções, a utilização de tais cartas possui uma importante, as vezes são as únicas ferramentas para o estudo da área e delimitação de unidades de paisagem. Através dela podese fazer conclusões, já que uma boa parte da qualidade ambiental está relacionada com o tipo de utilização do solo.

O atributo negativo poluição podendo ser tanto sonora ou do ar, contribuem diretamente para reduzir a qualidade de vida das cidades. Com o aumento de veículos em circulação, além de piorar o transito, fazem com que a quantidade de poluentes na atmosfera também aumente e consequentemente essas zonas sofrem com a poluição atmosférica e sonora proveniente desses veículos, entre outros. (NUCCI, 2008).

Nucci (op. cit.) destaca que a densidade populacional é um atributo negativo que pode alterar ou diminuir a qualidade ambiental de um determinado local. Sendo diretamente relacionada com desconforto, riscos de doenças, deficiência no abastecimento em geral. problemas na eliminacão e deposicão de lixo. mal-estar. ruídos. poluicão. 
congestionamento nas ruas, escassez de espaços livres para o lazer. A alta densidade está relacionada com as condições econômicas da população, falta ou inadequado planejamento e infraestrutura urbana (LIMA, 2012).

Com a verticalização das edificações ocorre também um aumento da densidade populacional que leva a uma diminuição da qualidade ambiental. Os impactos no ambiente gerados pela verticalização são de fácil identificação, como impermeabilização total do solo, aumento da densidade demográfica, diminuição do espaço livre, diminuição da insolação, aumento do volume construído, podendo altera a dinâmica dos ventos e acarreando na formação de microclimas alterando o conforto térmico da população. Em consequência desses primeiros impactos aparecem: uma sobrecarga da rede viária, de esgoto, de água, de eletricidade, coleta e deposição de lixo, etc. (NUCCI, 2008).

Lima (2012) destaca que o atributo negativo referente aos desertos florísticos relacionado à falta de vegetação em espaços urbanos têm uma grande importância para o ambiente e para a qualidade de vida da população através do conforto térmico e aumento das áreas permeáveis, entre outros fatores. A presença da vegetação, além de auxiliar para a melhoria da paisagem, ameniza o clima urbano, ajudando a qualidade ambiental urbana. Além disto, cumprindo funções estética, visual, ecológica e de lazer muito importantes para a vida social da cidade (MINAKI; AMORIM, 2012).

Nucci (2008) conclui-se que em lugares com baixa quantidade de vegetação inferior a 5\% ou sua ausência, a qualidade ambiental é bem inferior da desejável. Entretendo, não se pode concluir que em áreas com mais de 5\% de cobertura vegetal a qualidade ambiental é aceitável. Oke (1976) considera um índice de cobertura vegetal na faixa de $30 \%$ como sendo o recomendável para proporcionar um adequado equilíbrio térmico em áreas urbanas. A presença de espaços livres públicos, além de contribuir para a melhoria da paisagem, pode amenizar o clima urbano, favorecendo a qualidade ambiental urbana (MINAKI; AMORIM, op. cit.).

A relação do atributo negativo enchentes ou áreas sujeitas aos alagamentos estão relacionadas com a impermeabilização, que causa uma diminuição da infiltração da água no solo e um aumento do escoamento superficial. Associado à canalização de córregos, no qual faz com que a água da chuva que cai na cidade flua com maior rapidez para os principais córregos da cidade, que não conseguem dar vazão ao grande volume de água. A capacidade de vazão do rio e também diminuída pelo assoreamento ocasionado pelo constante remanejamento de terras devido ao crescimento desenfreado da cidade (NUCCI, 2008).

\section{Processos Metodológicos}

Para avaliar e mapear a qualidade ambiental da zona urbana de Salto do Jacuí/RS foi utilizado uma adaptação da metodologia desenvolvida por Nucci (1996) quando estudou a qualidade ambiental e o adensamento urbano no distrito de Santa Cecília, localizado no município de São Paulo. Com esse estudo foram escolhidos atributos negativos para determinar a qualidade ambiental sendo eles os seguintes: déficit de espaços livres, cobertura vegetal (desertos florísticos), verticalização, usos poluidores, densidade populacional, áreas de alagamentos e usos do solo ou da terra.

De acordo com Nucci (1998) a soma dos atributos negativos indicaria as seguintes classes de qualidade ambiental para a zona urbana do Salto do Jacuí: uso do solo, poluição, espaços livres, verticalidade das edificações, pontos de enchentes, densidade populacional e cobertura vegetal.

- Presença de 5 a 7 atributos - baixa qualidade ambiental;

- Presença de 3 a 5 atributos - média qualidade ambiental e,

- Presença de 1 a 2 atributos - alta qualidade ambiental. 
O mapeamento dos atributos negativos e o posterior cruzamento de mapas tendo em vista determinar a qualidade ambiental urbana no Salto do Jacuí, foram realizados no software de Geoprocessamento ArcGis10. Esta metodologia propõe a construção de cartas de qualidade ambiental urbana, baseado no levantamento e representação cartográfica de atributos negativos (NUCCI, et. al., 2005).

Com base na imagem de satélite do Software Google Earth do Salto do Jacuí, a imagem foi georreferenciada no ArcGis, sendo identificados os critérios que foram usados para fazer a carta de uso solo e mapeados também quantificados os espaços livres e a cobertura vegetal (desertos florísticos). Para a elaboração da carta de déficit de espaços livres, foi utilizado o índice de $5 \mathrm{~m}^{2}$ de espaços livres para uso de cada habitante como o valor menos restritivo de acordo com o valor encontrado por Nucci (2008).

Segundo NUCCI (1998) para a elaboração da carta de "desertos florísticos” a qual foi levado em consideração Oke (1973 apud LOMBARDO, 1985) segundo o mesmo considera um índice na faixa de $30 \%$ como recomendável para um favorável balanço térmico em áreas urbanas, sendo que áreas com índice de cobertura vegetal inferior a 5\% determinaria características semelhantes a um deserto.

Em trabalhos de campo juntamente com imagens de satélite foram levantados usos consideráveis possivelmente poluidores, considerando-se apenas o que pode ser observado da calçada, para a elaboração da carta de usos poluidores. Sendo eles: oficinas mecânicas, postos de combustíveis, estacionamentos, revendas de automóveis, depósitos, transportadoras, silos e armazéns, agropecuárias, as usinas hidrelétricas, entre outras.

Para mapear os pontos de alagamentos foram utilizados como base a carta topográfica de Nova Jacuí, com o mapa de uso da terra e entrevistas informais com moradores locais da cidade do Salto do Jacuí, a fim de identificar os pontos de alagamento. Para realizar a carta urbana de densidade demográfica foi delimitada com base nos setores censitários do IBGE.

Os dados coletados foram organizados nas seguintes cartas temáticas: déficit de espaços livres, cobertura vegetal (desertos florísticos), verticalização, usos potencialmente poluidores, pontos de alagamentos e usos do solo ou da terra. A representação e integração de tais atributos foram elaboradas no software ArcGis 10, gerando a carta de qualidade ambiental através da ferramenta Intersect, definida pelo cruzamento das cartas dos atributos negativos. As cartas de cada um desses atributos indicaram os locais onde se espera que haja problemas em relação à qualidade ambiental.

Conforme Lima (2013) esta metodologia possui como fundamental mecanismo a exibição de atributos ambientais negativos para sua posterior análise integrada, com base na união destas informações para chegar a um resultado final, ou seja, a carta de qualidade ambiental. Quando estas cartas são manuseadas e sobrepostas através do emprego de ferramentas de geoprocessamento que visam o cruzamento de mapas (ex: Intersect do Arcgis) permitem a formação do mapa síntese com as informações espacializadas da qualidade ambiental da área estudada.

\section{Análise e Discussão dos Resultados}

Para analisar e mapear a qualidade ambiental urbana do Salto do Jacuí foram quantificados e espacializados em cartas os seguintes atributos negativos conforme a metodologia proposta pelo autor: uso do solo, poluição, verticalização, densidade populacional, desertos florísticos, déficit de espaços livres e alagamentos.

A carta de uso do uso do solo, conforme Minaki e Amorim (2012), é de extrema importância para compreender a organização espacial da cidade, contribuindo para as ações do planejamento urbano na identificação de possíveis problemas. 
Para este trabalho foram determinadas seis classes de uso do solo: a) área de mineração; b) uso urbano (residencial, comercial, industrial, outros); c) Reserva Indígena Mbyá Guarani; d) Vegetação (primaria e silvicultura); e) Lavouras, pastagens, solo exposto (em área urbana) e f) Lavouras, pastagens, solo exposto (em área rural).

A carta de uso do solo do Salto do Jacuí - RS, é composta por uma área mista, sendo boa parte da área urbana constituída por lavouras em maior proporção do leste a sul da área residencial e uma pequena parte do oeste ao norte, a vegetação está presente em pequenos fragmentos na área urbana. Na parte nordeste a norte está presente a silvicultura que é representada pelo reflorestamento feito pela empresa Companhia Estadual de Energia Elétrica (CEEE), na parte norte da área urbana do município encontra-se o reservatório Engenheiro Maia Filho. A sudoeste da área urbana está a área de mineração.

No bairro centro a presença de uso misto de sua área, sendo integrado por comercio, bancos, escolas, restaurantes, residências, entre outros, sendo que o comercio predomina nessa área da cidade; o bairro Harmonia é composto por pequenas indústrias de grãos, com maior concentração de oficinas mecânicas, postos de combustíveis, com o principal acesso a cidade, sendo o único acesso com presença de pavimentação asfáltica;

Os bairros Residencial Nova Jacuí (CEEE) e Nossa Senhora dos Navegantes, são bairros residenciais, os quais não há presença de comércio em geral, sendo bairros "planejados" em comparação aos demais, sendo composto pela população de classe média e alta; os bairros Portão, Menino Deus e Cruzeiro compostos pela maior parte da população, apresentando pequenos comércios (minimercados, oficinas mecânicas, entre outros), onde predomina a população de baixa renda. Na área urbana do Salto do Jacuí as residências apresentam um padrão, em sua maioria são residências unifamiliares de um a dois pavimentos e em locais isolados apresentam alguns prédios que não ultrapassam os 4 pavimentos, localizado no bairro centro.

Em relação ao atributo poluição ou fontes poluidoras foram feitas análises qualitativas do fluxo de veículos nas principais vias de circulação do Salto do Jacuí-RS, mapeou-se os usos poluidores relacionados à postos de gasolina, oficinas mecânicas, agroindústrias, locais de mineração, estacionamento de carros e caminhões, rodoviária e serviços públicos com grande circulação de pessoas em busca dos mesmos.

A poluição sonora e do ar estão diretamente ligadas a redução da qualidade de vida das cidades. O trafego de automóveis pelas cidades são os maiores fatores de poluição, fazendo com que a cidade perca qualidade de vida, não tendo dúvida de que podem ser a principal fonte de poluição atmosférica e sonora (MARCUS; DETWYLER, 1972). Com o aumento de carros em circulação, além de piorar o trânsito com engarrafamentos, fazem com que a quantidade de poluentes na atmosfera aumente, além do aumento do estresse, aumento no número de atropelamentos, entre outros. (NUCCI, 1998).

Nucci (op. cit.) também destaca que não precisa de muito esforço para a comprovação que as serralherias, mecânicas, funilarias e postos de gasolina são fontes poluidores. Mecânicas, funilarias e postos de gasolina trabalham diretamente com automóveis, motos, ônibus e caminhões e, consequentemente, o afluxo de veículos para e nesses locais é muito alto; deste modo essas áreas sofrem com a poluição atmosférica e sonora originada desses veículos.

Além do que, o próprio funcionamento desses estabelecimentos gera poluição, que não ficam restritos aos seus interiores, fazendo uso das calçadas para seus serviços, como nota-se em muitas oficinas e postos de gasolina pelas áreas das cidades. As serralherias apresentam como principal incômodo a geração de ruídos, mas ocorre também um aumento do movimento de veículos em seu entorno e a utilização das calçadas para os serviços.

Analisando o mapa da poluição da área urbana do Salto do Jacuí, nota-se que as áreas mais poluídas são os acessos a área urbana, o centro da cidade, as principais vias de circulação que ligam os bairros ao centro e o acesso as 
áreas de mineração e à Usina Leonel de Moura Brizola. A poluição ou fontes poluidoras, segundo a metodologia de Nucci, afetam um raio de até 100 metros dessas fontes.

Nucci (2008) destaca que os impactos no ambiente originados pela verticalização vão de aspectos facilmente identificados, como impermeabilização parcial ou total do solo, aumento da densidade demográfica, diminuição do espaço livre, diminuição da insolação, aumento do volume construído, até as consequências mais complicadas de serem estudadas, como a alteração na dinâmica dos ventos e criação de microclimas alterando o conforto térmico da população.

Como consequência desses primeiros impactos aparecem: uma sobrecarga da rede viária, de esgoto, de água, de eletricidade, coleta e deposição de lixo, etc. Ocorre também um aumento do escoamento das águas de esgotamento e pluviais. Nos espaços livres remanescentes é comum a aglomeração de usuários. Formam-se pequenas ilhas de calor que se unindo podem conceber em uma grande ilha, alterando assim o mesoclima urbano e ocasionando desconforto térmico (NUCCI, 2008).

No Salto do Jacuí há a ausência de prédios residenciais acima de 5 pavimentos, a cidade é composta em sua maioria por casas de um a dois pavimentos, as edificações com maior verticalização, são caixas d'agua e silos de grãos localizados no bairro Harmonia.

A densidade populacional ou demográfica é um outro aspecto negativo que interfere na qualidade ambiental das cidades, diminuindo a qualidade ou alterando-a. Constantemente, a alta densidade está relacionada com as condições econômicas da população, falta ou ineficaz planejamento e infraestrutura urbana. A concentração de habitantes em uma determinada área pode influir direta ou indiretamente na pressão exercida sobre o ambiente, considerando seus aspectos físicos, e podem estar relacionadas, também, com áreas de ocupação irregular e ilegal da cidade, Lima (2011).

Como analisado a carta da densidade populacional no Salto do Jacuí, nota-se que as maiores densidades se concentram nos setores censitários pertencentes aos bairros Harmonia e Menino Deus. Os bairros Portão e Cruzeiro e uma pequena parte do bairro Centro, possuem uma densidade populacional menor comparados aos bairros anteriores citados. Já os bairros Nova Jacuí e Nossa Senhora dos Navegantes possuem uma menor densidade em comparação com os anteriores, e o bairro Vila da Cruz Alta tem a menor densidade de toda a cidade em estudo.

A vegetação no espaço urbano assume importância para o ambiente e para a qualidade de vida da população através do conforto térmico e aumento das áreas permeáveis, entre outros fatores (LIMA, 2012). Conforme o critério adotado por Nucci (1998) são necessários $5 \mathrm{~m}^{2}$ de espaços livres públicos por habitante. A área urbana de Salto do Jacuí/RS conta com aproximadamente $140.000 \mathrm{~m}^{2}$, entre parques, praças, monumentos e balneários públicos. A população conta com cerca de 11.200 habitantes. Nesse sentido, há uma relação de $12,5^{2}$ de espaços públicos para cada habitante em Salto do Jacuí, número duas vezes e meia maior do que o mínimo estabelecido pelo autor. Assim, Salto do Jacuí/RS não possui déficit de espaços públicos livres.

Sendo considerados espaços livres, os espaços urbanos ao ar livre destinados a usos como caminhadas, descanso, passeio, prática de esportes, recreação e entretenimento e horas de ócio, podendo ser privados ou públicos, mas potencialmente coletivos (CAVALHEIRO et. al., 1999). Para Minaki e Amorim (2012), a presença dessas áreas, além de contribuir para a melhoria da paisagem, pode amenizar o clima urbano, favorecendo a qualidade ambiental urbana.

Em relação ao atributo deserto florísticos nota-se que grande parte da zona urbana de Salto do Jacuí possui cobertura vegetal abaixo de 5\% e que se caracterizam como um deserto florístico se localizam nos bairros Centro, 
Harmonia, Menino Deus, Cruzeiro, Vila Cruz Alta e Portão, sendo que as áreas com cobertura vegetal acima de 5\% encontram-se nos bairros Nova Jacuí e Navegantes.

A presença de vegetação no espaço urbano, seja por meio natural ou por silvicultura, assume uma importante influência para o ambiente e para a qualidade de vida da população, seja ela pela melhoria da paisagem, aumentando o conforto térmico, amenizando o clima urbano. Além do mais a vegetação cumpre um papel na estética, visual, ecológica e de lazer muito importantes para a vida social da cidade.

Em lugares com baixa quantidade de vegetação inferior a 5\% ou sua ausência, a qualidade ambiental é bem inferior da desejável. Entretendo, não se pode concluir que em áreas com mais de 5\% de cobertura vegetal a qualidade ambiental é aceitável. Nestes casos devem-se considerar conjuntamente todas as outras possíveis variáveis (NUCCI, 2008).

Em relação ao atributo negativo "enchentes" ou áreas susceptíveis aos alagamentos na zona urbana de Salto do Jacuí, nota-se que é entre os bairros Portão e Cruzeiro, sendo o único lugar susceptível a "enchentes" na cidade. Se encontrando desprovido de mata auxiliar e assoreamento.

De acordo com Pompêo (2000) as "enchentes" são fenômenos naturais que são originados por chuvas de elevada magnitude, podendo ser provocadas pelo transbordamento de cursos d'agua, resultantes da urbanização e de mudanças nos ciclos hidrológicos nas cidades.

As principais causas dos alagamentos estão correlacionadas com a impermeabilização parcial ou total da cidade, e um aumento do escoamento superficial. Isso, associado a canalização de córregos naturais, fazem com que a agua da chuva que cai sobre a cidade flua com maior rapidez para os principais corpos d'água, que não conseguem dar vazão ao grande volume. A capacidade de vazão do rio é também diminuída pelo assoreamento ocasionado pelo constante remanejamento de terras devido ao crescimento desenfreado e desorganizado da cidade (NUCCI, 2008).

Segundo Minaki e Amorim (op. cit.) Um subsistema do sistema urbano, chamado ciclo hidrológico, é mais um integrante que atua no desequilíbrio da qualidade ambiental. Como exemplo, tem-se o aumento da vazão devido ao escoamento canalizado e a diminuição da evapotranspiração, tornando-se comum na cidade. Este indicador, quando não abordado corretamente pelo planejamento urbano, pode se tornar muito dispendioso não só em termos financeiros.

Nas cidades cujo planejamento da drenagem urbana é ausente, ou mal aplicados, tornam-se comuns problemas como as inundações, alagamentos entre outros. Isso se torna um agravante pelo fato de que a população de classe baixa sofre as consequências mais severas por causa do mau ordenamento do solo urbano, causando transtornos dos mais variados em toda a cidade, reduzindo com isso a qualidade de vida e ambiental das áreas afetadas.

Ao considerar os aspectos negativos de cada atributo: uso do solo, poluição, verticalização, densidade populacional, déficit de espaços livres públicos, desertos florísticos, áreas de enchentes, fontes poluidoras, foram utilizados para elaborar em um SIG no software Arcgis, formando a carta de qualidade ambiental de Salto do Jacuí-RS.

A partir da ferramenta Intersect deste mesmo software foi feito álgebra de mapas das informações adquiridas de cada atributo. Gerando a representação das áreas que apresentaram a soma dos atributos negativos; as que tiveram ausência de atributo foram classificadas, nesse caso, como de alta qualidade ambiental em relação aos indicadores utilizados nesta pesquisa.

Por conseguinte, a reprodução da qualidade ambiental resultante da sobreposição dos símbolos considerados aspectos negativos de cada atributo. A área que possuir a maior ocorrência dos atributos possui a baixa qualidade ambiental em relação as que apresentam menos presença desses atributos. A qualidade ambiental de Salto do Jacuí foi classificada conforme Nucci: 
- $\quad$ Presença de 5 a 7 atributos - baixa qualidade ambiental;

- $\quad$ Presença de 3 a 4 atributos - média qualidade ambiental;

- $\quad$ Presença de 1 a 2 atributos - alta qualidade ambiental.

Analisando a figura 2 nota-se que a área urbana do Salto do Jacuí, tem ausência de atributos negativos de 5 a 7 , os quais apresentam uma baixa qualidade ambiental. A presenta de 4 atributos negativos acorre apenas em 2 pontos da área urbana que são, entre os bairros Portão e Cruzeiro, que apresentam os seguintes critérios: enchente, poluição, densidade populacional, desertos florísticos e um ponto no bairro Nova Jacuí que apresenta: poluição, densidade populacional, desertos florísticos e a verticalização.

A parte central da cidade juntamente com uma faixa do bairro Menino Deus, Portão, Nossa Senhora dos Navegantes, Cruzeiro, Residencial Nova Jacuí, e Harmonia, há presença de 3 atributos negativos que são: Densidade populacional, poluição e desertos florísticos, sendo a parte central dos mesmos, que são áreas de media qualidade ambiental, além da influência de atributos negativos apresentam as agroindústrias, produzindo impactos socioambientais, emissão de poluentes, poluição sonora, maior adensamento e fluxo de veículos e população e uma maior presença de desertos florísticos.

À medida que há o afastamento da área central dos bairros em direção a periferia, começam a surgir presença de áreas verdes, áreas de lazer, diminuição dos atributos negativos, como adensamento populacional, poluição, e um aumentando da cobertura vegetal e da qualidade ambiental.

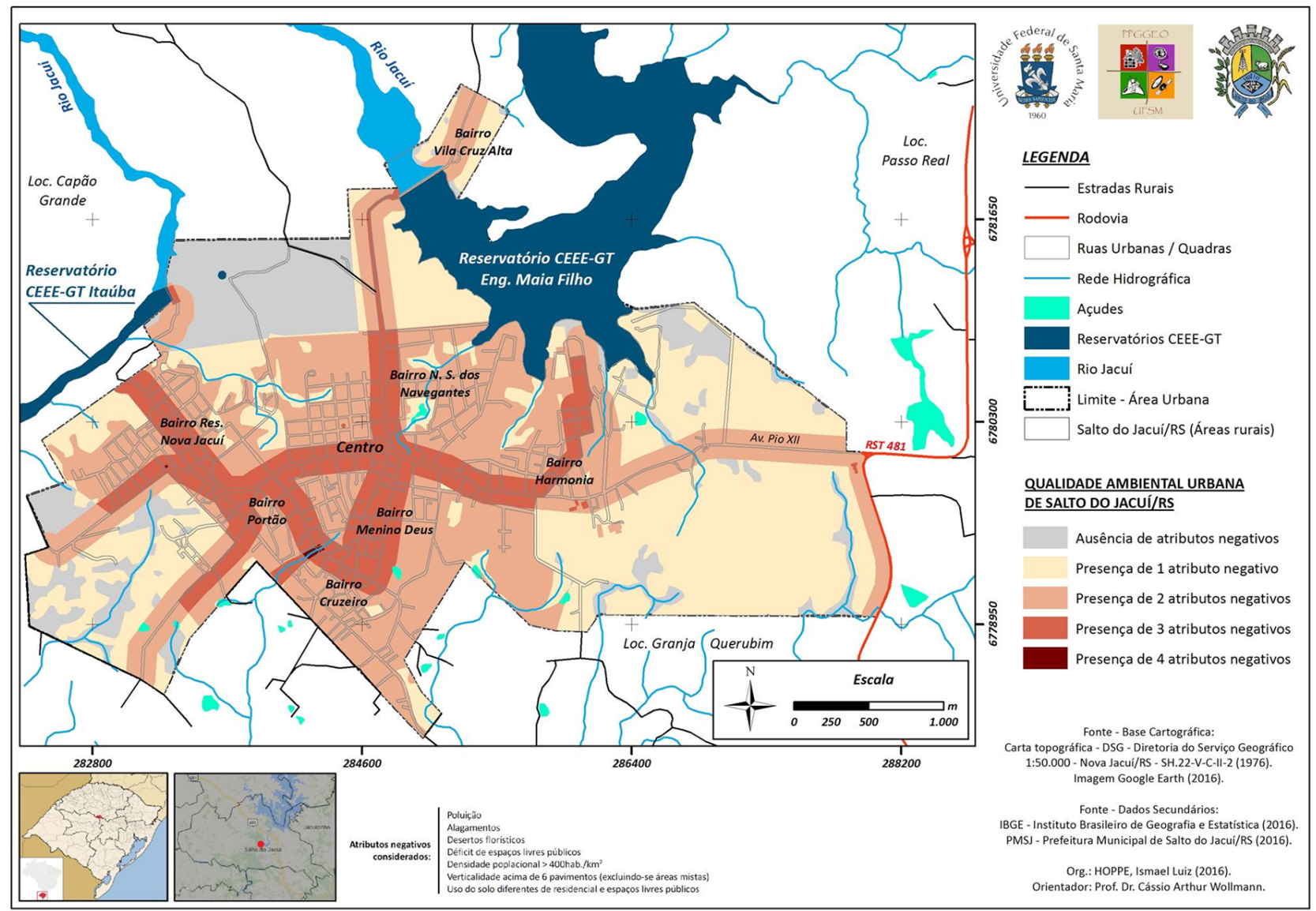

Figura 2 - Carta da qualidade ambiental urbana de Salto do Jacuí/RS 
A área rururbana de Salto do Jacuí contém apenas um atributo negativo que é o deserto de cobertura vegetal e áreas com ausências de atributos negativos, representados em cinza que são fragmentos florestais, pois essas áreas contém um número menor ou nulo de habitantes, não contendo estradas pavimentadas, zonas comercias, zonas com verticalização, pontos de alagamentos, áreas poluidoras.

\section{Conclusões}

A cidade de Salto do Jacuí RS, tem ausência de atributos negativos de 5 a 7, os quais representam uma baixa qualidade ambiental. A presenta de 4 atributos negativos acorre apenas em 2 pontos da área urbana, com isso, pode-se dizer que a área urbana de Salto do Jacuí apresenta média e alta qualidade ambiental. Essa qualidade é reflexo dos serviços urbanos; o Salto é uma cidade que vive em função das usinas, não tem grandes industrias, funcionalismo público, serviços para atender o povo do interior e cidades vizinhas, ou seja, é uma cidade que não tem grandes expectativas de crescimento, então ela até possui uma qualidade, mas não porque foi planejada, mas porque suas relações socioeconômicas a deixaram do jeito que é sem maiores expectativas.

Como medidas para reduzir os problemas e visando a uma melhoria da qualidade ambiental urbana é necessário: evitar o adensamento urbano e populacional e a verticalização da cidade; o poder público deve implantar mais espaços verdes com cobertura vegetal e espações livres públicos. Para a diminuição da poluição urbana o município poderia apresentar transporte coletivo urbano, assim diminuir o volume de carros na cidade.

Outas melhorias que poderão ser tomadas pelos governantes, com o intuito de melhorar o ambiente urbano são adequar as construções urbanas, diminuir o uso de asfalto na cidade, substituindo-o por calçamento vem a auxiliar a diminuição do acumulo de águas nas ruas (ou sarjetas). Fazer o reflorestamento de área de prevenção permanente que pode impedir o extravasamento dos cursos d'água, com isso, esses e outros fatores vem a melhorar a qualidade ambiental da área urbana. Desse modo, esta pesquisa tem o intuito de motivar pesquisas futuras de clima urbano visando a qualidade ambiental do Salto do Jacuí interfere no clima.

\section{Agradecimentos}

“O presente trabalho foi realizado com apoio do Programa Nacional de Cooperação Acadêmica da Coordenação de Aperfeiçoamento de Pessoal de Nível Superior - CAPES/Brasil - No Processo: 88881.068465/2014/01 Projeto $n^{\circ}$ 071/2013 CAPES/PROCAD

\section{Referências}

ASSIS, W. L. O sistema clima urbano do município de Belo Horizonte na perspectiva têmporo-espacial. 2010. 319 f. Tese (Pós-Graduação em Geografia) Instituto de Geociências da Universidade Federal de Minas Gerais - UFMG. Belo Horizonte, 2010.

CAVALHEIRO, F. Urbanização e alterações ambientais. In: TAUK, S.M. Análise Ambiental: uma visão multidisciplinar, São Paulo: UNESP-FAPESP, 1991, p. 88-99.

DOUGLAS, I. The urban environment. London: Edward Arnold (Publishers) Ltda, 1983, 229p.

FUNDAÇÃO DE ESTATÍSTICA E ECONOMIA. FEE Dados. Disponível em: . Acesso em 15 de abril de 2017. 
IBGE. Cidades@: censo 2010. Disponível em: <http://www.ibge.gov.br/cidadesat/topwindow.htm?1 >. Acesso em: 15 abril 2017.

LANDSBERG, H.E. Man-Made Climatic Changes. Science, n.170, p. 1265-1274, 1970.

LIMA, V; AMORIM, M.C.C.T. A importância das áreas verdes para a qualidade ambiental das cidades. Revista Formação, Presidente Prudente, nº13, p. 139-165, 2006.

LIMA, A.P.; AMORIM, M.C.de C.T. Contribuição ao Estudo de Clima Urbano em cidades de pequeno porte: o caso de Rosana/SP. In: VIII SIMPÓSIO BRASILEIRO DE CLIMATOLOGIA GEOGRÁFICA. 2008, Alto do Caparaó-MG. Anais... Alto do Caparaó: Universidade Federal de Uberlândia, 2008.

LIMA, N. R. de, et al. Clima urbano no Brasil: análise e contribuição da metodologia de Carlos Augusto de Figueiredo Monteiro. Revista Geonorte, Edição Especial 2, Manaus, v.2, n.5, p.626 - 638, 2012.

LIMA, V. A sociedade e a natureza na paisagem urbana: análise de indicadores para avaliar a qualidade ambiental. 2013. 359f. Tese (Doutorado em Geografia) - Programa de Pós-Graduação em Geografia-Faculdade de Ciências e TecnologiaUniversidade Estadual Paulista, Presidente Prudente, 2013.

LOMBARDO, M.A. Ilhas de calor nas metrópoles: o exemplo de São Paulo. São Paulo: HUCITEC, 1985. 244 p.

MARCUS, M.G; DETWYLER, T.R. Urbanization and environment. Bermont: Duxburg Press, 1972, 286p.

MINAKI, C.; AMORIM, M.C.de C. Clima Urbano e Conforto Térmico em Guararapes/SP. In: VII SIMPÓSIO BRASILEIRO DE CLIMATOLOGIA GEOGRÁFICA. 2006, Rondonópolis-MT. Anais... Rondonópolis: Universidade Federal de Mato Grosso, 2006.

MONTEIRO, C. A. F. A dinâmica climática e as chuvas no Estado de São Paulo. São Paulo: IGEOG/USP, 1973. $129 \mathrm{p}$

MONTEIRO, C. A. F.. Teoria e clima urbano. 1976. 181f. Tese (Livre Docência) - Instituto de Geografia, Universidade de São Paulo, São Paulo, 1976 b.

MONTEIRO, C. A. F.. Qualidade ambiental - Recôncavo e regiões limítrofes. Salvador: Centro de Estatísticas e Informações, 1987, 48p.

MONTEIRO, C. A. F.. Por um suporte teórico e prático para estimular estudos geográficos de clima urbano no Brasil. GEOSUL, Florianópolis - SC, nº 9 - Ano V - $1^{\circ}$ semestre, p. 07-19. 1990a.

MORATO, R.G. Análise espacial e desigualdade ambiental no município de São Paulo. 2008. Tese (Doutorado em Geografia Física) -FFLCH/USP. São Paulo, 2008.

NUCCI, J.C. Qualidade ambiental e adensamento: um estudo de Planejamento da Paisagem do Distrito de Santa Cecília. 1996. 229 f. Tese (Doutorado em Geografia Física). Universidade de São Paulo, São Paulo.

NUCCI, J.C Metodologia para determinação da qualidade ambiental urbana. Revista do Departamento de Geografia, São Paulo, n.12, p.209-224, 1998.

NUCCI, J.C. Análise sistêmica do ambiente urbano, adensamento e qualidade ambiental. Revista Ciências Biológicas e do Ambiente, São Paulo, v. 1, n. 1, p. 73- 88, 1999.

NUCCI, J.C Qualidade ambiental e adensamento urbano: um estudo de Ecologia e Planejamento da Paisagem aplicado ao distrito de Santa Cecília (MSP). 2.ed. Curitiba: O autor, 2008, 150p. 
NUCCI, J.C. Mapeamento da qualidade ambiental urbana. Anais... do International Congress on Environmental Planning and Management - Environmental Challenges of Urbanization, Brasília, UCB, 2005.

OKE, T.R. Inadvertent Modification of the City Atmosphere and the Prospects for Planned Urban Climates. proc.symp.meteorol. Related to urban and regional land-use planning, 1976, Asheville. Proceedings. Geneva: World meteorol., 1976.

PERLOFF, H. S. La calidad del médio ambiente urbano. Barcelona/Espanha: Oikos-tau S.A, 1973.

POMPÊO, C. A. Drenagem Urbana Sustentável. Revista Brasileira de Recursos Hídricos, ABRH, v. 5, n. 1, p. 15-23, jan./mar., 2000. 